J. Amer. Soc. Hort. ScI. 118(2):181-187. 1993.

\title{
A Two-dimensional, Dynamic Model for Root Growth Distribution of Potted Plants
}

\author{
De-Xing Chen ${ }^{1}$ and J. Heinrich Lieth ${ }^{2}$ \\ Department of Environmental Horticulture, University of California, Davis, CA 95616
}

Additional index words. root growth, root spatial distribution, mathematical model, potted plant, chrysanthemum,

Dendranthema $\times$ grandiflorum

\begin{abstract}
A two-dimensional mathematical model was developed to describe the time course of root growth and its spatial distribution for container-grown plants, using chrysanthemum [Dendranthema xgrandiflorum (Ramat.) Kitamura] as the model system. Potential root growth was considered as consisting of several concurrent processes, including branching, extension, and death. Branching rate was assumed to be related sigmoidally to existing root weight density. Root growth extension rate was assumed to be proportional to the existing root weight density above some threshold root weight density in adjacent cells. The senescence rate of root weight density was assumed to be proportional to existing root mass. The effects of soil matric potential and temperature on root growth were quantified with an exponential function and the modified Arrhenius equation, respectively. The actual root growth rate was limited by the amount of carbohydrate supplied by the canopy to roots. Parameters in the model were estimated by fitting the model to experimental data using nonlinear regression. Required inputs into the model included initial root dry weight density distribution, soil temperature, and soil water potential data. Being a submodel of the whole-plant growth model, the supply of carbohydrates from canopy to roots was required; the total root weight incremental rate was used to represent this factor. Rather than linking to a complex whole-plant $\mathbf{C}$ balance model, the total root weight growth over time was described by a logistic equation. The model was validated by comparing the predicted results with independently measured data. The model described root growth dynamics and its spatial distribution well. A sensitivity analysis of modeled root weight density to the estimated parameters indicated that the model was more sensitive to carbohydrate supply parameters than to root growth distribution parameters.
\end{abstract}

The principal functions of roots are the uptake of water and nutrients, the transport of these materials into the vascular system, and anchorage of the plant in the root medium. Root distribution and growth are important in determining water and nutrient uptake, and in affecting plant water and nutrient balance. Despite this importance, few models for root growth dynamics have been developed, probably because the processes involved are not well understood and are difficult to observe.

Several whole-plant models that include the representation of below-ground processes have been developed for field crops (see Luxmoore and Stolzy, 1987). Greenwood et al. (1974) and Barnes et al. (1976) developed models of nutrient uptake and growth for prediction of vegetable crop response to fertilizer application under varying weather and soil conditions. Huck and Hillel (1983) developed a model for root growth and water uptake of field crops that accounted for the $\mathrm{C}$ balance, water balance, and vertical distribution of roots. Lambert and Baker (1982) combined current knowledge of soil water physics and data on root growth with hypotheses concerning root growth and water and nitrate uptake to form a two-dimensional dynamic simulation model (RHIZOS) that Acock et al. (1983) incorporated into their comprehensive soybean [Glycine max (L.) Merr.] model GLYCIM. Brugge and Thornley (1985) and Brugge (1985) developed a theoretical model using the diffusion analogy for grass root mass and its vertical distribution. All of these models were developed for plants growing in field soil. The applicability of these models to the individual potted plant is limited, since container configuration, irrigation practices, and rooting me-

Received for publication 4 Feb. 1992. Accepted for publication 15 July 1992. The cost of publishing this paper was defrayed in part by the payment of page charges. Under postal regulations, this paper therefore must be hereby marked advertisement solely to indicate this fact.

'Postdoctoral Research Associate. Current address: Natural Resource Ecology Laboratory, Colorado State Univ., Fort Collins, CO 80523.

${ }^{2}$ Associate Professor and Extension Specialist, corresponding author. dium differ significantly. A two-dimensional model for water transport in the root zone and in the plant was developed previously for potted chrysanthemum (Chen and Lieth, 1992). While the effects of root distribution and growth on water uptake were taken into account, root growth dynamics throughout the root zone were not incorporated. The objective of this work was to develop a two-dimensional, dynamic model of root growth spatial distribution for potted plants as a submodel for inclusion in whole-plant simulation models of potted plant systems.

\section{Materials and Methods}

The symmetry of the potted plant root zone suggested the use of a cylindrical coordinate system that characterized depth and radial distance from the center of the pot. The container volume of the root medium was divided into layers of equal thickness, $\Delta \mathrm{z}$, and concentric cylindrical shells of equal thickness, $\Delta \mathrm{r}$. Root system growth and spatial distribution were represented approximately by the dynamics of the root weight density in the resulting medium cells (Fig. 1a). State variables and rates are defined for each of these cells and represented by subscripted variables where the subscripts are the layer number, $i$, and the shell number, $j$. The geometric shape of each cell is then a cylindrical shell with inner radius $(\mathrm{j}-1) \Delta \mathrm{r}$, outer radius $\mathrm{j} \Delta \mathrm{r}$, and volume

$$
\Delta \mathrm{v}_{\mathrm{i}, \mathrm{j}}=\pi(2 \mathrm{j}-1) \Delta r^{2} \Delta \mathrm{z}
$$

Symbols and values of the model variables and parameters are summarized in Table 1.

Root growth was considered to consist of several concurrent processes, including branching, extension, and death. We adopted the approach described by Hillel and Talpaz (1976) in our work. Root growth involves proliferation in regions of the root medium where roots are already present and where none exist. Root growth is constrained by several factors, including the availability of photosynthate or the partitioning of carbohydrate 


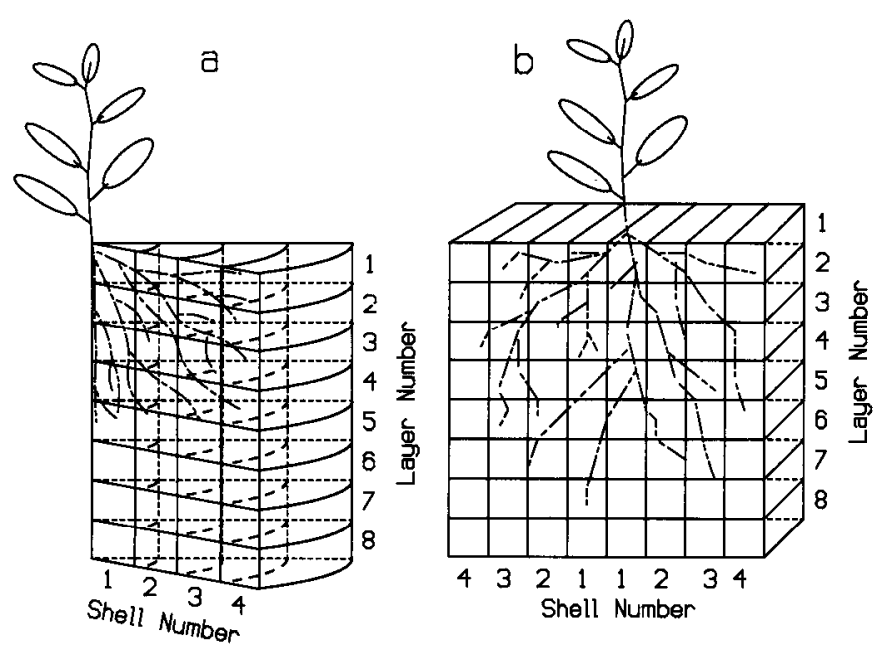

Fig. 1 Schematic: (a) the division of the container volume and (b) the coordinate system of the central slice.

Table 1. Identification of variables and parameters used.

\begin{tabular}{|c|c|c|}
\hline Symbol & Variable or parameter & Value and units \\
\hline $\mathrm{b}$ & Parameter in Eq. [3] & $0.127 /$ day \\
\hline B & Proliferation rate of root growth & $\mathrm{kg} \cdot \mathrm{m}^{-3} \cdot \mathrm{day}^{-1}$ \\
\hline $\mathrm{d}$ & Parameter in Eq. [11] & $0 /$ day \\
\hline $\mathrm{D}$ & Decrease rate of root wt density & $\mathrm{kg} \cdot \mathrm{m}^{-3} \cdot \mathrm{day}^{-1}$ \\
\hline $\mathrm{E}$ & Root extension growth rate & $\mathrm{kg} \cdot \mathrm{m}^{-3} \cdot \mathrm{day}^{-1}$ \\
\hline $\mathrm{e}$ & Component of root extension rate & $\mathrm{kg} \cdot \mathrm{m}^{-2} \cdot \mathrm{day}^{-1}$ \\
\hline $\mathrm{i}$ & Subscript of layer no. & \\
\hline I & Maximum of I & \\
\hline $\mathrm{j}$ & Subscript of shell no. & \\
\hline $\mathrm{J}$ & Maximum of $\mathrm{j}$ & \\
\hline $\mathbf{N}$ & Total no. days & day \\
\hline $\mathrm{p}$ & Parameter in Eq. [13] & 10,311 \\
\hline $\mathrm{Q}$ & Parameter variable in Eq. [17] & \\
\hline PR & Potential root growth rate & $\mathrm{kg} \cdot \mathrm{m}^{-3} \cdot \mathrm{day}^{-1}$ \\
\hline$q$ & Parameter in Eq. [13] & 59 \\
\hline$s_{1}, s_{2}, s_{3}$ & Adjacent section arcas between cells & $m^{2}$ \\
\hline $\mathrm{S}_{\mathrm{O}}$ & Sensitivity & $\%$ \\
\hline $\mathrm{t}$ & Time & day \\
\hline $\mathrm{T}_{\mathrm{o}}$ & Optimal temp & $295^{\circ} \mathrm{K}$ \\
\hline $\mathrm{T}_{\mathrm{s}}$ & Soil temp & ${ }^{\circ} \mathrm{K}$ \\
\hline$u$ & Parameter in Eq. [13] & 17,343 \\
\hline W & Root wt density & $\mathrm{kg} \cdot \mathrm{m}^{-3}$ \\
\hline $\mathrm{W}_{\mathrm{r}}$ & Total root wt & $\mathrm{kg}$ \\
\hline $\mathrm{W}_{\mathrm{m}}$ & Maximum root wt density & $7.491 \mathrm{~kg} \cdot \mathrm{m}^{-3}$ \\
\hline$W_{\mathrm{rm}}$ & Maximum total root $w t$ & $0.00306^{\circ} \mathrm{kg}$ \\
\hline $\mathrm{W}_{\text {thr }}$ & Threshold root wt density & $3.648 \mathrm{~kg} \cdot \mathrm{m}^{-3}$ \\
\hline$\alpha$ & Parameter in Eqs. [8]-[10] & $0.0029 \mathrm{~m} \cdot \mathrm{day}^{-1}$ \\
\hline$\beta$ & Parameter in Eq. [12] & 0.00276 \\
\hline$\eta$ & Parameter in Eq. [15] & 2.907 \\
\hline$\mu$ & Parameter in Eq. [15] & 0.085 \\
\hline$\psi$ & Soil matric potential & $\mathrm{kPa}$ \\
\hline$\psi_{\mathrm{thr}}$ & Threshold soil matric potential & $-859 \mathrm{kPa}$ \\
\hline$\Delta v$ & Vol of medium cell & $\mathrm{m}^{-3}$ \\
\hline$\Delta \mathrm{r}$ & Increment of radius (thickness of shell) & $\mathrm{m}$ \\
\hline$\Delta Q$ & Change in parameter $\mathrm{Q}$ & \\
\hline$\Delta W_{i, j}(t)$ & Change in $W_{i, j}(t)$ & $\mathrm{kg} \cdot \mathrm{m}^{-3} \cdot \mathrm{day}^{-1}$ \\
\hline$\Delta W_{i, j} / \Delta t$ & Rate of change of root wt density & $\mathrm{kg} \cdot \mathrm{m}^{-3} \cdot \mathrm{day}^{-1}$ \\
\hline$\Delta \mathrm{W}_{\mathrm{t}} / \Delta \mathrm{t}$ & Total root wt growth rate & $\mathrm{kg} \cdot \mathrm{day}^{-1}$ \\
\hline$\Delta z$ & Depth of layer & $\mathrm{m}$ \\
\hline
\end{tabular}

between shoot and root. Environmental factors affecting root growth include soil moisture, nutrient concentration, salinity, aeration, chemical toxicity, and soil temperature. Of these, only the effects of soil moisture, temperature, and carbohydrate availability were considered here. We assumed that adequate nutrients were supplied and that the soil was well aerated. In simulation of root growth, a distinction was made between potential and actual root growth.

The potential root growth rate in cells $i, j$ was described as:

$$
P R_{i, j}=B_{i, j}+E_{i, j}-D_{i, j}
$$

where $\mathrm{PR}_{\mathrm{i}, \mathrm{j}}$ is the potential growth rate of root weight density, $B_{i, j}$ is the rate of root weight increase by branching, $E_{i, j}$ is the rate of root weight increase by extension, and $D_{i, j}$ is the rate of root weight decrease by senescence and death.

Branching rate, $B_{i, j}$, was assumed to depend on root weight density, $\mathrm{W}_{\mathrm{i}, \mathrm{j}}$, and be influenced by soil matric potential, $\psi_{\mathrm{i}, \mathrm{j}}$, and soil temperature, $\mathrm{T}$, with the following relationship:

$$
B_{i, j}=b W_{i, j}\left[1-\left(W_{i, j} / W_{m}\right)\right] f_{1}\left(\psi_{i, j}\right) f_{2}\left(T_{s}\right)
$$

where $\mathrm{W}_{\mathrm{m}}$ is the maximum root weight density (root dry weight per unit soil volume, kilograms per cubic meter) and b is a constant. The functions $f_{1}$ and $f_{2}$ represent the effects of soil matric potential and temperature, respectively, on root growth. Their values range from 0 to 1 .

$$
\begin{aligned}
& E_{i, j} \text { is computed with: } \\
& \qquad E_{i, j}=\left(e_{i-1, j} s_{1}+e_{i, j-1} s_{2}+e_{i, j}+s_{3}\right) / \Delta v_{i, j}
\end{aligned}
$$

where $e_{i-1, j}, e_{i j-1}$, and $e_{i, j+1}$ represent the amount of root material growing into cells $\mathrm{i}, \mathrm{j}$ from the adjacent cells. No upward root extension is considered. These rates are expressed in kilograms per square meter per day and are multiplied by the area (square meters) of the common surfaces, $\mathrm{s}_{1}, \mathrm{~s}_{2}$, and $\mathrm{s}_{3}$ :

$$
\begin{aligned}
& \mathrm{s}_{1}=\pi \Delta r^{2}(2 \mathrm{j}-1) \\
& \mathrm{s}_{2}=2 \pi(\mathrm{j}-1) \Delta r \Delta \mathrm{z} \\
& \mathrm{s}_{3}=2 \pi \mathrm{j} \Delta r \Delta \mathrm{z}
\end{aligned}
$$

and divided by the cell volume to obtain the rates in kilograms per cubic meter per day. These three components of root extension growth rate were assumed to be related to the existing root mass and soil environmental condition by the following equations:

$$
\begin{gathered}
=\alpha \max \left\{\left(\mathrm{W}_{\mathrm{i}-1, \mathrm{j}}-\mathrm{W}_{\mathrm{thr}}\right), 0\right\} \\
{\left[1-\left(\mathrm{W}_{\mathrm{i}, \mathrm{j}} / \mathrm{W}_{\mathrm{m}}\right)\right] \mathrm{f}_{1}\left(\psi_{\mathrm{i}-1, \mathrm{j}}\right) \mathrm{f}_{2}\left(\mathrm{~T}_{\mathrm{s}}\right)} \\
=\alpha \max \left\{\left(\mathrm{W}_{\left.\left.\mathrm{i}, \mathrm{j}-1-\mathrm{W}_{\mathrm{thr}}\right), 0\right\}}\left[1-\left(\mathrm{W}_{\mathrm{i}, \mathrm{j}} / \mathrm{W}_{\mathrm{m}}\right)\right] \mathrm{f}_{1}\left(\psi_{\mathrm{i}, \mathrm{j}-1}\right) \mathrm{f}_{2}\left(\mathrm{~T}_{\mathrm{s}}\right)\right.\right. \\
=\alpha \max \left\{\left(\mathrm{W}_{\mathrm{i}, \mathrm{j}}+\frac{\left.\left.1-\mathrm{W}_{\mathrm{thr}}\right), 0\right\}}{\left[1-\left(\mathrm{W}_{\mathrm{i}, \mathrm{j}} / \mathrm{W}_{\mathrm{m}}\right)\right] \mathrm{f}_{1}\left(\psi_{\mathrm{i}, \mathrm{j}}+1\right) \mathrm{f}_{2}\left(\mathrm{~T}_{\mathrm{s}}\right)}\right.\right.
\end{gathered}
$$

where $\alpha$ is a constant and $\mathrm{W}_{\text {thr }}$ is the threshold of the root weight density for root extension into adjacent medium cells (Bar-Yosef et al., 1982). $\mathrm{e}_{0, \mathrm{j}}, \mathrm{e}_{\mathrm{i}, 0}$, and $\mathrm{e}_{\mathrm{i}, \mathrm{J}+1}$ were defined to be zero since they were outstde the root zone. $J$ is the highest iteration of the shell number, $j$.

For simplification, the decrease of root weight density by senescence and death was assumed to be proportional to the existing root weight density:

$$
D_{i, j}=d W_{i, j}
$$

Westgate and Boyer (1985) reported the root elongation rate decreased exponentially with decreasing water potential. An exponentially decreasing function with soil matric potential was 
adopted here to model $f_{1}$, so that

$$
f_{1}(\psi)=1-e^{-\beta\left(\psi-\psi_{(h r}\right)}
$$

Where $\psi_{\text {thr }}$ is the threshold soil matric potential for root growth and $\beta$ is the coefficient. The soil temperature index function, $\mathrm{f}_{2}$, was modelled using a modified Arrhenius equation (Johnson and Thornley, 1985):

$$
f_{2}\left(T_{s}\right)=\frac{\left[1+\exp \left\{q-\left(u / T_{o}\right)\right\}\right] \exp \left\{\left(p / T_{s}\right)-\left(p / T_{o}\right)\right\}}{1+\exp \left\{q-\left(u / T_{s}\right)\right\}}
$$

where $\mathrm{p}, \mathrm{q}$, and $\mathrm{u}$ are parameters, and $\mathrm{T}_{\mathrm{o}}$ is the optimal temperature for root growth.

The actual root growth rate, $\Delta \mathrm{W}_{\mathrm{i}, \mathrm{j}} / \Delta \mathrm{t}$, depends on the current total supply of carbohydrates from the canopy to the roots. The algorithm used in RHIZOS (Bar-Yosef et al., 1982) was adopted here:

$$
\frac{\Delta W_{i, j}}{\Delta t}=\frac{P R_{i, j}}{\sum_{i} \sum_{j} P R_{i, j} \Delta v_{i, j}} \frac{\Delta W_{r}}{\Delta t}
$$

where $\mathrm{A} \mathrm{W}_{\mathrm{r}} / \Delta \mathrm{t}$ is the total root weight growth rate to represent the supply rate of carbohydrates. Total root weight growth over time was described by a logistic equation

$$
\mathrm{W}_{r}=\mathrm{W}_{\mathrm{rm}} /\left(1+\mathrm{e}^{\eta-\mu \mathrm{t}}\right)
$$

where $\mathrm{W}_{\mathrm{r}}$ is the total root weight, $\mathrm{W}_{\mathrm{rm}}$ is the maximum of the total root weight, $\eta$ and $\mu$ are parameters, and $t$ is time. Total root growth rate, $\Delta \mathrm{W}_{\mathrm{r}} / \Delta \mathrm{t}$, was calculated as

$$
\frac{\Delta W_{r}}{\Delta t}=W_{r}(t+1)-W_{r}(t)
$$

\section{Experimental data collection}

Model development (Expt. I). Rooted cuttings of chrysanthemum 'Bright Golden Anne' (Yoder Brothers, Barberton, Ohio) were planted on 28 Aug. 1990 in 13-cm-diameter plastic containers filled with $1000 \mathrm{ml} \mathrm{UC}$ mix [1 peat moss : 1 sand : 1 redwood sawdust (by volume)] at a density of one cutting per pot. The pots were spaced rim to rim and grown in a greenhouse at Univ. of California, Davis, during Summer-Fall 1990. The tensiometer-based computerized drip irrigation system developed by Lieth and Burger (1989) was used to apply two 5-min irrigations/day (at $\approx 0900$ and $1500 \mathrm{HR}$ ) and to continuously monitor soil moisture tension. Half-strength Hoagland's solution 2 (Hoagland and Arnon, 1950) was used for all irrigations. A temperature sensor (National Semiconductor, LM35) and tensiometer $(8 \mathrm{~cm}$ long with a $2-\mathrm{cm}$ porous cup) were embedded in the center of the root volume of a representative pot. Soil moisture tension and temperature were averaged hourly and recorded using a data logger.

Nine and 36 potted plants were selected for nondestructive and destructive experiments, respectively. A pool of 32 additional plants was maintained to replace plants harvested from the bench. All plants were grown under long-day conditions (night interruption from 2200 to 0200 HR using 100-W incandescent lights) for 7 days after planting. Thereafter, short days were imposed by shading plants with black cloth from 1700 to 0800 HR. Canopy height was measured from the surface of the medium to the top of the canopy every 3 or 4 days starting on day 11 (7 Sept.) for the nine plants selected for nondestructive observation. Destructive harvests were made on the same days by removing the leaves from three plants, measuring their total leaf area using a LI-COR-3000 leaf area meter (LI-COR, Lincoln, Neb.), and placing them in a paper bag. Stems were also harvested and bagged.

The pots were then inverted on a table, and the entire rooting medium was removed in one solid block. A 3-cm-thick slice was then cut from the center of this block (Fig. lb) and divided into an $8 \times 8$ grid of sections, and the roots were washed from each. Samples were combined for the quadrants with the same layer and shell labels (see Fig. lb) and bagged. The medium cut from either side of the central slice was also washed, and the roots were extracted, combined, and bagged. Dry weights were measured after the bags were in a drying oven at $75 \mathrm{C}$ for $\approx 2$ weeks. The root dry weight distribution was determined from the root material in the central slice. The total root dry weight was determined by summing root dry weights from the entire pot.

Model validation (Expt. II). The same experiment was repeated from 10 Dec. 1990 to 22 Feb. 1991 for model validation. Plants were grown in 14-cm-diameter pots filled with $\approx 1400$ ml UC mix. Plants were maintained as in Expt. I. Destructive harvests were made every week. The central slice of the medium was divided into a $4 \times 6$ grid-of sections to sample root weight density.

\section{Model calibration}

The daily mean soil matric potential and the daily mean soil temperature were calculated for model input from the hourly average data collected with the data logger. The optimal soil temperature for root growth, T,, was estimated at $22 \mathrm{C}$ based on the report by Mortensen (1982).

The nonlinear regression (NLIN) procedure of the Statistical Analysis System (SAS, 1987) was used for other parameter estimations. We assumed the pattern of root elongation response to soil matric potential was similar to the root elongation response to plant water potential. The root elongation data were based on Westgate and Boyer (1985). To normalize the data, observed values were divided by the maximum rate. The parameters $\beta$ and $\psi_{\text {thr }}$ of the soil matric potential index function were estimated by fitting Eq. [12] to the normalized root elongation rate. Parameters $\mathrm{p}, \mathrm{q}$, and $\mathrm{u}$ of the soil temperature index function were estimated by fitting Eq. [13] to the normalized data of Mortensen (1982) on chrysanthemum total fresh weight at various root zone temperatures, assuming that the pattern for root growth is similar. Parameters $W_{r m}, \eta$, and $\mu$ of the total root weight growth equation were estimated by fitting Eq. [15] to the total root weight data. Since the root growth distribution parameters $\mathrm{b}, \mathrm{d}, \mathrm{W}_{\mathrm{thr}}, \mathrm{W}_{\mathrm{m}}$, and $\alpha$ are in differential equations, they cannot be estimated directly. Estimates were obtained by subjecting the entire simulation model for the root growth dynamics to the nonlinear regression procedure. First, these root growth differential equations were integrated based on the assumed values of the parameters to get root dry weight density dynamics in all medium cells for the whole growth season. Then NLIN was used to minimize the sum of squared deviations of the simulation by readjusting parameter values until some convergence criterion was met. This was carried out on the root dry weight density distribution data of Expt. I. The first fitting result showed that parameter $\mathrm{d}$ was not significantly different from 0 ; hence the regression was rerun with $d=0$. Setting $d$ to zero is quite plausible, since this means that root senescence and death were insignificant in our experiment. A 1-day time step was used in the simulation.

The simulation model was coded into a computer program 
Table 2. Sensitivities (\%) of modeled root weight density to estimated parameters.

\begin{tabular}{ccc}
\hline \hline & $\mathrm{S}_{\mathrm{Q}}$ \\
\hline Parameter $(\mathrm{Q})$ & 0.45 \\
$\mathrm{~b}$ & 7.5 \\
$\mathrm{~W}_{\mathrm{m}}$ & 0.50 \\
$\alpha$ & 3.5 \\
$\mathrm{~W}_{\mathrm{thr}}$ & 0.02 \\
$\beta$ & 0.01 \\
$\psi_{\mathrm{thr}}$ & 5.1 \\
$\mathrm{p}$ & 46.1 \\
$\mathrm{q}$ & 40.4 \\
$\mathrm{u}$ & 39.1 \\
$\eta$ & 55.4 \\
$\mu$ & 40.0 \\
\hline
\end{tabular}

(using TURBO PASCAL) and implemented with these estimated values of parameters on an IBM-AT compatible personal computer. The performance of the simulation model was validated using data sets from Expt. II. Since the environmental variables (light, temperature, etc.) were different from those of Expt. I, Eq. [15] fit to the total root weight data to mimic total root growth during Expt. II.

\section{Sensitivity analysis}

In the application of any model, it is important to know the accuracy of parameter estimates and how the model responds to perturbations in these estimates. This issue was addressed in a sensitivity analysis whereby the model sensitivity So (percent) to perturbation of any parameter (denoted here as Q) is computed by comparing the results of the simulation with and without this perturbation $\Delta Q$ (Thornley and Johnson, 1991) so that:

$$
S_{Q}=\frac{100}{N \cdot I \cdot J} \sum_{t}^{N} \sum_{i, j}^{I, J}\left|\frac{\Delta W_{i, j}(t) / W_{i, j}(t)}{\Delta Q / Q}\right|
$$

where $\Delta \mathrm{W}_{\mathrm{i}, \mathrm{j}}$ is the change that this produces in $\mathrm{W}_{\mathrm{i}, \mathrm{j}}$, $\mathrm{I}$ is the total number of layers, and $\mathrm{N}$ is the total number of days. In this study a $10 \%$ parameter perturbation was used, so that $\Delta \mathrm{Q} /$ $\mathrm{Q}=0.1$. Parameters with larger So have larger effects on the final simulated results. To look at the sensitivity of model in relation to parameters of the environmental index functions $f_{1}$ and $\mathrm{f}_{2}$, the simulations were run on soil water potential and temperature vertical distribution conditions whose gradients were $0.2 \mathrm{kPa} \cdot \mathrm{cm}^{-1}$ and $-0.3 \mathrm{C} / \mathrm{cm}$, respectively.

\section{Results}

The normalized root elongation rate was reduced. by decreasing water potential (Fig. 2). The soil matric potential index function, $f$, fit the normalized root elongation rate data with an $R^{2}$ value of 0.967 . The parameters $\beta$ and $\psi_{\text {thr }}$ in Eq. [12] were estimated to be 0.0028 and $-859 \mathrm{kPa}$ with asymptotic SE of 0.0004 and 28, respectively. Westgate and Boyer (1985) reported that the water potential at which the elongation of maize nodal roots ceased was $-1000 \mathrm{kPa}$. The temperature index function, $\mathrm{f}_{2}$, fit the data with an $R_{2}$ value of 0.993 (Fig. 3). The parameters p, q, and $\mathrm{u}$ in Eq. [13], were estimated to 10,311, 59 , and 17,343 with asymptotic SE of 4456, 6.7, and 1853, respectively.

The daily mean soil matric potential varied between about -0.6 and $-1.0 \mathrm{kPa}$ during Expt. I (Fig. 4a). The daily average soil temperature of Expt. I fluctuated between $\approx 19$ and $22 \mathrm{C}$,

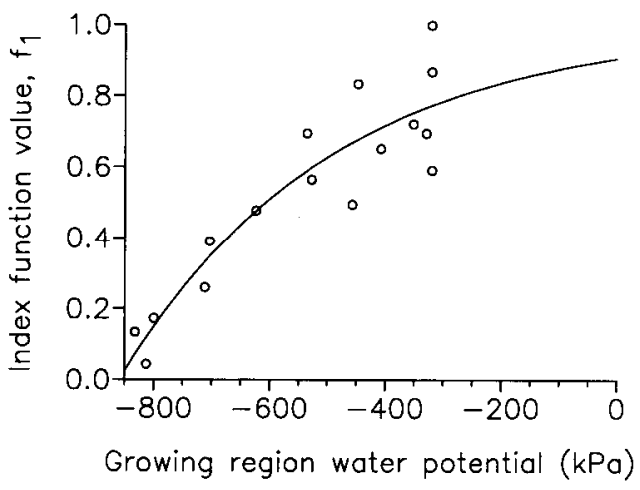

Fig. 2 Fitted curve of matric potential index function (Eq. [12]) and normalized root elongation data $(\bigcirc)$ calculated based on the data of Westgate and Boyer (1985).

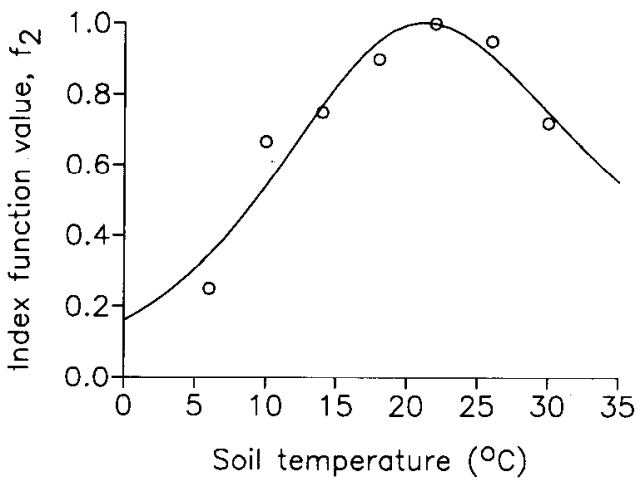

Fig. 3 Fitted curve of soil temperature index function (Eq. [13]) and normalized total plant fresh weight data ( $\bigcirc$ ) of Mortensen (1982).

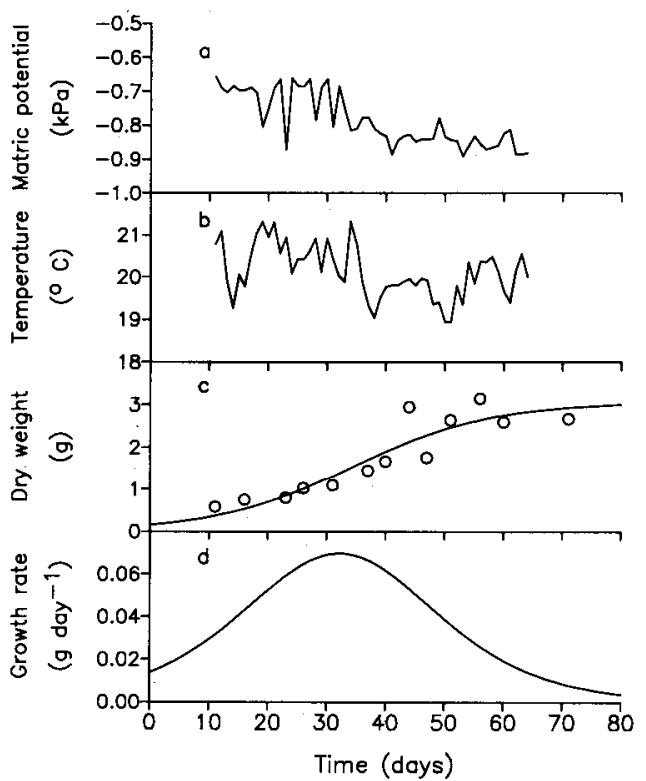

Fig. 4 (a) Daily mean soil matric potential, (b) daily mean soil temperature, (c) measured ( $O$ ) and predicted (curve) total root weight, and (d) the predicted total root growth rate for Expt. I. Day $0=28$ Aug. 1990.

and its mean over the entire growing season was about 20C (Fig. 4b). The total root weight changed with time in a sigmoid pattern (Fig. 4c). Fitting the logistic equation to the measured data resulted in a curve with an $R^{2}$ value of 0.997 for Expt. I. The parameters $\mathrm{W}_{\mathrm{rm}}, \eta$, and $\mu$, in Eq. [15] were estimated to be 
$3.06 \mathrm{~g}, 2.91$, and 0.085 with asymptotic SE of $0.458,0.758$, and 0.029 , respectively. The time course of the total root weight growth rate was asymmetric bell-shaped, reaching a maximum at about day 30 (Fig. 4d).

The nonlinear regression of the model to root weight density distribution data resulted in an $R^{2}$ value of 0.940 . The estimates for the root growth distribution parameters $b, W_{m}, W_{\text {thr }}$ and $\alpha$ in the model were $0.127 /$ day, $7.491 \mathrm{~kg} \cdot \mathrm{m}^{-3}, 3.648 \mathrm{~kg} \cdot \mathrm{m}^{-3}$, and 0.0029 m-day-' with asymptotic SE of $0.396,0.434,0.825$, and 0.218 , respectively. The asymptotic SE was large in the estimations of the branching parameter, $b$, and extension parameter, $\alpha$. This large SE may have been due to measurement errors and the simplification of assuming that root branching and extension were independent of root age and homogeneous in all directions and that the spatial distribution of soil matric potential and temperature was negligible. The predicted root weight density time courses matched the measured data well in most cells (Fig. 5). In the top layer, however, the model underestimated the measured data late in the growing period. The root weight density time courses displayed a sigmoid pattern, particularly in top center cells. Root weight density decreased with depth and radial distance from the center. The maximum root weight density appeared in top central cells. The change of root weight density with depth decreased with the radial distance, particularly in top layers.

During Expt. II the average of daily mean soil matric potential was about $-0.7 \mathrm{kPa}$, its maximum about $-0.4 \mathrm{kPa}$ (Fig. 6a). Mean soil temperature was $\approx 19 \mathrm{C}$ (Fig. $6 \mathrm{~b}$ ). Total root weight over time was described well by Eq. [15] with the parameters

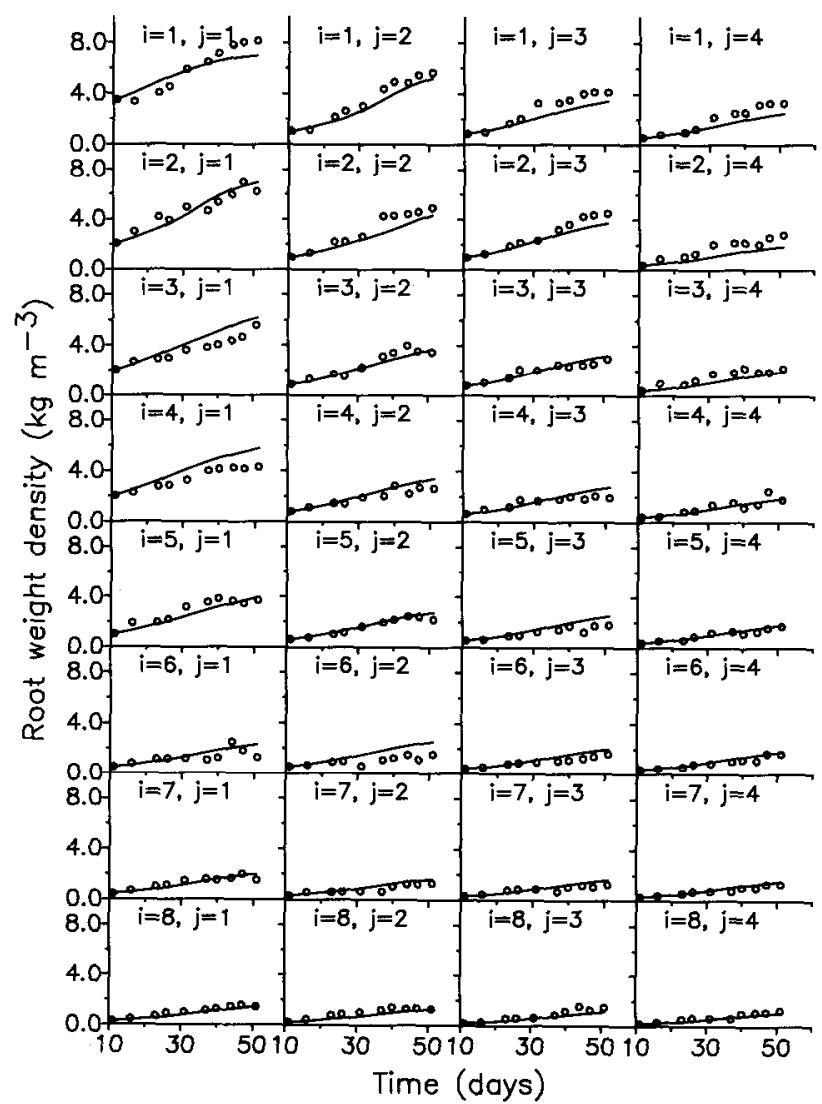

Fig. 5 Simulated (curves) and measured ( $\mathrm{O}$ ) root weight density in each cell at all locations in the root zone in Expt. I; $i$ is the layer number $(\mathrm{i}=1$ : top, $\mathrm{i}=8$ : bottom) and $\mathrm{j}$ is the shell number $(\mathrm{j}=$ 1: center, $\mathrm{j}=4$ : outside)

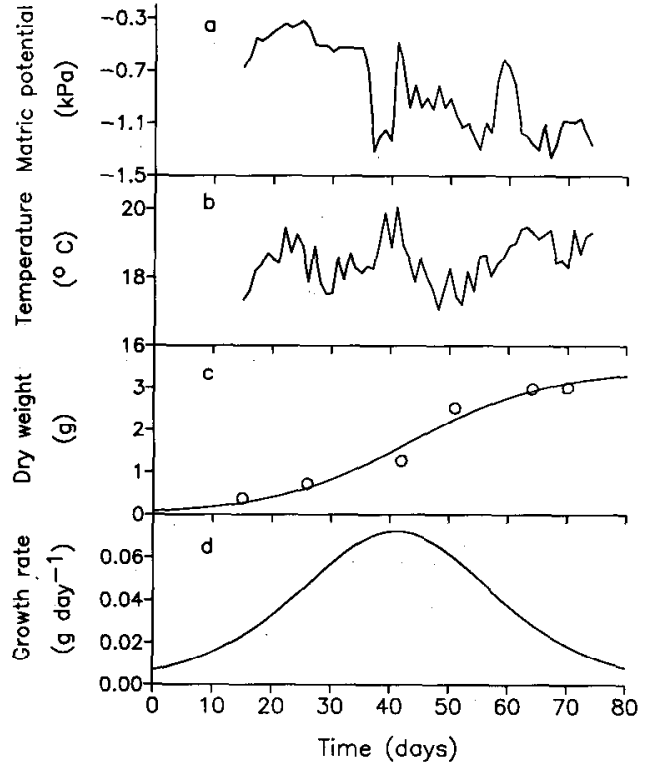

Fig. 6 (a) Daily mean soil matric potential, (b) daily mean soil temperature, (c) measured ( $O$ ) and predicted (curve) total root weight, and (d) the predicted total root growth rate over time for Expt. II. Day $0=10$ Dec. 1990 .

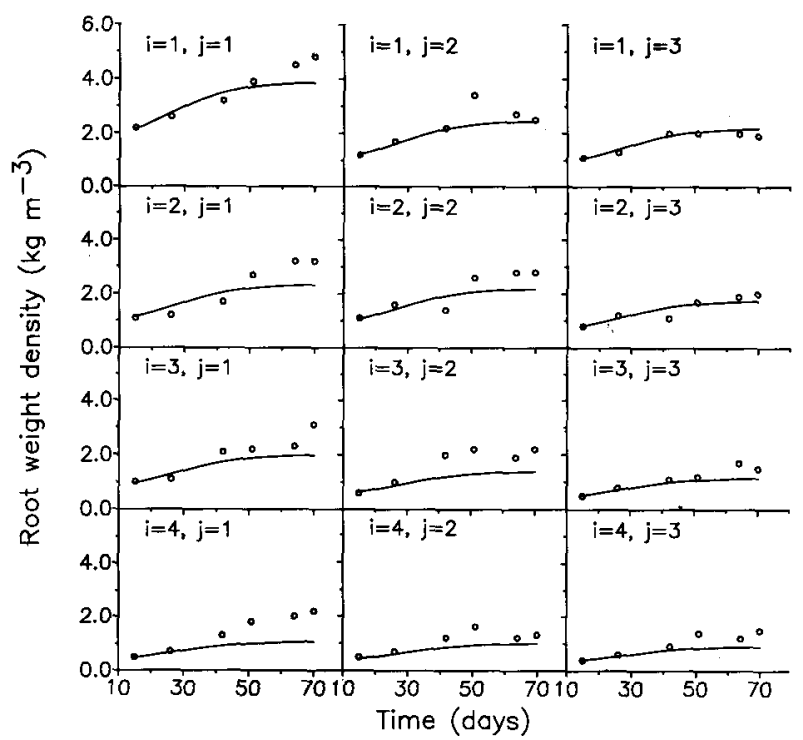

Fig. 7 Predicted (curves) and measured ( $\bigcirc$ ) root weight density in each cell at all locations in root zone in validation experiment; $i$ is the layer number $(\mathrm{i}=1$ : top, $\mathrm{i}=4$ : bottom) and $\mathrm{j}$ is the shell number $(\mathrm{j}=1$ : center, $\mathrm{j}=3$ : outside).

$\mathrm{W}_{\mathrm{rm}}, \eta$, and $\mu$ of $3.44 \mathrm{~g}, 3.72$, and 0.085 (Fig. 6c). The $\mathrm{R}^{2}$ value of the fitted curve was equal to 0.991. Total root growth rate over time (Fig. 6d) had the same pattern as in Expt. I.

Using this information and the values of root growth distribution parameters estimated in Expt. I, the model was used to predict root weight density distribution over time for the conditions from Expt. II. The predicted root weight density agreed well with measured data (Fig. 7), decreasing with depth and radial distance. The linear regression line of the predicted vs. observed root weight density was not significantly different from 1:1 correspondence line $(P=0.001)$.

To detail the time course of root growth and its vertical distribution in different shells, three-dimensional graphics of sim- 
ulated root weight density for Expt. I were developed (Fig. 8). Root weight density increased sigmoidally with growing season, particularly in top central layers. It decreased with depth, except in the top layer, for all shells. In the outer shell, root weight density profiles were flatter than in the central shell. Root weight density was greatest in the middle of the pot and $\approx 3 \mathrm{~cm}$ below the medium surface.

The sensitivity analysis of the model to the parameters showed that the simulated root weight density distribution was more sensitive to parameters, $W_{r m}, \eta$, and $\mu$, which described the carbohydrate supply from shoot, than to root growth distribution parameters, $b, \mathrm{~W}_{\mathrm{m}}, \mathrm{W}_{\text {thr }}$ and $\alpha$. This result suggested that the environmental condition that determined the supply of carbohydrates to the root system had a larger effect on root growth and distribution. Under assumed soil temperature profiles, the model was very sensitive to the parameters in temperature index function $f$,. When soil temperature and water potential were assumed uniform throughout the root zone in our simulations, the sensitivities of $\beta, \psi_{\text {thr }}, \mathrm{p}, \mathrm{q}$, and $\mathrm{u}$, the parameters for the water potential index and temperature index functions, were all zero. This finding indicates that these parameters reflected the effects of the spatial distribution of soil water potential and temperature on root system growth and spatial distribution pattern.

\section{Discussion}

A previous study by Chen and Lieth (1992) developed a mathematical model of water transport accounting for the effect of root zone size and spatial distribution. As with most crop growth models that quantify plant uptake of water and solutes from soils, it required a quantitative description of the root system. The root water uptake model required information like root length density and changes in that distribution over time. Sampling the root system and measuring its properties over time and space in soil during a whole growing season is labor-intensive and sometimes impossible. Therefore, building a model to simulate root system dynamics and its properties under various environmental conditions is useful. In the present study, a two-dimensional, dynamic model was developed to describe the time course of root growth and its spatial distribution for container-grown plants. Root growth was considered to consist of several concurrent processes, including branching, extension, and death in the model. Branching rate and extension rate of root growth depended upon existing root weight density, soil water potential, and temperature. Actual root growth was limited by the supply of carbohydrates from the shoot. The simulation results agreed well with measured root weight density data (Figs. 5 and 7).

The model provides a useful tool for studying the effects of soil temperature and moisture environment on root growth and
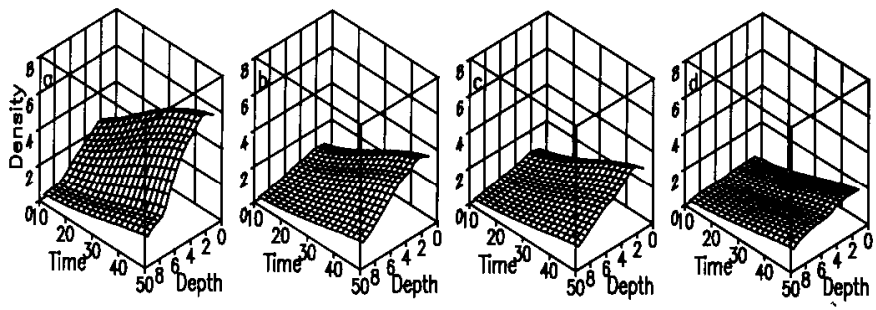

Fig. 8 Simulated time course of root weight density $\left(\mathrm{kg} \cdot \mathrm{m}^{-3}\right)$ and vertical distribution during Expt. I in the shells at (a) radius 0-1.5 $\mathrm{cm}$, (b) radius 1.5-3.0 $\mathrm{cm}$, (c) radius $3.0-4.5 \mathrm{~cm}$, and (d) radius $4.5-6.0 \mathrm{~cm}$. The unit of time is day. its spatial distribution. In combination with nonlinear regression parameter estimation, the model is useful for making inferences about several root growth characteristics that are difficult to measure directly, such as root branching, extension, and death. For instance, in our experiment, root death was relatively insignificant, and the threshold of the root weight density for root extension was $\approx 3.6 \mathrm{~kg} \cdot \mathrm{m}^{-3}$, which was very close to the value $3.7 \mathrm{~kg} \cdot \mathrm{m}^{-3}$ used by Bar-Yosef et al. (1982) in their model. The mechanistic nature of the model will allow it to be applied to other plant root systems by customizing root growth distribution parameters. Similarly, the simple link between the model and root growth through the carbohydrate supply from shoot makes incorporation into whole-plant growth model relatively easy, The sensitivity analysis showed that the carbohydrate supply parameters, $\mathrm{W}_{\mathrm{rm}}, \eta$, and $\mu$ had large effects on simulated root weight density distribution.

Equipment limitations precluded the examination of responses of root branching and extension to soil matric potential and wide ranges of temperature by experiment in our study. More experimentation is required to improve and/or validate the description of soil matric potential index (Eq. [12]) and soil temperature index functions (Eq. [13]). Additionally, the range of soil matric potential and temperature was small in the current work. Further experimentation under suboptimal soil water and temperature conditions is required for complete model validation. Particularly, these kind of data will be useful to determine the sensitivity of the model to soil conditions. Sensitivity analysis of the parameters in the environmental index functions showed that the model was sensitive to the spatial distribution of soil temperature and water potential. This means that not only the absolute values of soil temperature and water potential but also their spatial distribution patterns are important in determining root system spatial distribution.

It should also be noted that the rooting medium used in this study consisted of a highly porous artificial medium. Ornamental crops typically grown in this medium suffer significant water stress if matric potentials drop below $-10 \mathrm{kPa}$ (Lieth and Burger, 1989). Thus, potentials between 0 and $-5 \mathrm{kPa}$ were maintained. Consequently, interpretation of these data and this model must be handled with caution, particularly if media consisting of or including field soils are used since matric potentials under such conditions can be significantly lower.

Root branching, extension, and death are age-dependent and influenced by soil medium texture or physical properties. Our model does not deal with this age dependency of root growth, nor does it account for the restriction of soil aeration, nutrient, and medium texture. In principle, however, such factors can be incorporated into this model, given the quantitative relationships involved and the parameters that characterize them, in a manner similar to the functions $\mathrm{f}_{1}$ and $\mathrm{f}_{2}$. This model provided a description of root growth distribution for whole-plant growth model.

\section{Literature Cited}

Acock, B., V.R. Reddy, F.D. Whisler, D.N. Baker, J.M. Mckinion, H.F. Hodges, and K.J. Boote. 1983. The soybean crop simulator GLYCIM. Model Doc. 1982, Mississippi Agr. For. Expt. Sta., Mississippi State Univ., State College.

Barnes, A., D.J. Greenwood, and T.J. Cleaver. 1976. A dynamic model for the effects of potassium and nitrogen fertilizers on the growth and nutrient uptake of crops. J. Agr. Sci. 86:225-231.

Bar-Yosef, B., J.R. Lambert, and D.N. Baker. 1982. A simulation of root growth and soil processes. Sensitivity analysis and validation for cotton. Trans. Amer. Soc. Agr. Eng. 2.5:1268-1273.

Brugge, R. 1985. A mechanistic model of grass root growth and de- 
velopment upon photosynthesis and nitrogen uptake. J. Theoretical. Biol. 116:443-467.

Brugge, R. and J.H.M. Thornley. 1985. A growth model of root mass and vertical distribution dependent on carbon substrate from photosynthesis and with non-limiting soil conditions. Ann. Bot. 55:563577.

Chen, D.-X. and J.H. Lieth. 1992. Two-dimensional model of water transport in the root-zone and plant for container-grown chrysanthemum. Agr. For. Meteorol. 59:129-148.

Greenwood, D.J., J.T. Wood, and T.J. Cleaver. 1974. A dynamic model for the effects of soil and weather conditions on nitrogen response. J. Agr. Sci. 82:455-462.

Hillel, D. and H. Talpaz. 1976. Simulation of root growth and its effect on the pattern of soil water uptake by a nonuniform root system. Soil Sci. 121(5):307-312.

Hoagland, D.R. and D.I. Arnon. 1950. The water-culture method for growing plants without soil. Calif. Agr. Expt. Sta. Circ. 347, Berkeley, Calif.

Huck, M.G. and D. Hillel. 1983. A model of root growth and water uptake accounting for photosynthesis, respiration, transpiration, and soil hydraulics, p.273-333. In: D. Hillel (ed.). Advances in irrigation, Vol. 2, Academic, New York.
Johnson, I.R. and J.H.M. Thornley. 1985. Temperature dependence of plant and crop processes. Ann. Bot. 55:1-24.

Lambert, J.R. and D.N. Baker. 1982. RHIZOS: A simulator of root and soil processes. Tech. B. 1080, South Carolina Agr. Expt. Sta., Clemson.

Lieth, J.H. and D.W. Burger. 1989. Growth of chrysanthemum using an irrigation system controlled by soil moisture tension. J. Amer. Soc. Hort. Sci. 114(3):387-390.

Luxmoore, R.J. and L.H. Stolzy. 1987. Modeling below-ground processes of roots, the rhizosphere, and soil communities, p. 129156. In: K. Wisiol and J.D. Hesketh (eds.). Plant growth modeling for resource management. vol. II. CRC, Boca Raton, Fla.

Mortensen, L.M. 1982. Growth responses of some greenhouse plants to environment. II. The effect of soil temperature on Chrysanthemum $\times$ morifolium Ramat. Scientia Hort. 16:47-55.

Westgate, M.E. and J.S. Boyer. 1985. Osmotic adjustment and the inhibition, of leaf, root, stem and silk growth at lower potentials in maize. Planta 164:540-549.

SAS. 1987. SAS/STAT ${ }^{\mathrm{TM}}$ Guide for personal computers, Version 6 (ed.), SAS Inst., Inc. Cary, N.C.

Thornley, J.H.M. and I.R. Johnson. 1991. Plant and crop modelling. Clarendon Press, Oxford. p. 39-41. 